\title{
Electronic autoradiography of Ba-133 particle emissions; diffusion profiles in granitic rocks
}

\section{Muuri, Eveliina}

2019-07

Muuri , E , Sorokina , T, Donnard, J, Billon, S, Helariutta , K, Koskinen, L, Martin , A \& Siitari-Kauppi , M 2019 , ' Electronic autoradiography of Ba-133 particle emissions; diffusion profiles in granitic rocks ' , Applied Radiation and Isotopes , vol. 149 , pp. 108-113 . https://doi.org/10.1016/j.apradiso

http://hdl.handle.net/10138/304403

https://doi.org/10.1016/j.apradiso.2019.04.026

unspecified

acceptedVersion

Downloaded from Helda, University of Helsinki institutional repository.

This is an electronic reprint of the original article.

This reprint may differ from the original in pagination and typographic detail.

Please cite the original version. 


\title{
Electronic autoradiography of ${ }^{133}$ Ba particle emissions; diffusion profiles in granitic rocks
}

\author{
Eveliina Muuri $^{\mathrm{a}, *}$, Tatiana Sorokina ${ }^{\mathrm{a}}$, Jérôme Donnard ${ }^{\mathrm{b}}$, Sophie Billon ${ }^{\mathrm{c}}$, Kerttuli Helariutta ${ }^{\mathrm{a}}$, \\ Lasse Koskinen $^{\mathrm{d}}$, Andrew Martin ${ }^{\mathrm{e}}$, Marja Siitari-Kauppi ${ }^{\mathrm{a}}$ \\ ${ }^{a}$ Department of Chemistry, University of Helsinki, A.I. Virtasen aukio 1, 00560, Helsinki, Finland \\ ${ }^{\mathrm{b}}$ Ai4r, 2 Rue Alfred Kastler, 44307, Nantes, France

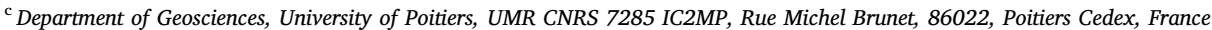 \\ ${ }^{\mathrm{d}}$ Posiva Oy, Finland \\ ${ }^{\mathrm{e}}$ Nagra (National Cooperative for the Disposal of Radioactive Waste), Wettingen, Switzerland
}

\section{H I G H L I G H T S}

- The spatial distribution of ${ }^{133} \mathrm{Ba}$ activity in granitic rocks was measured with two autoradiography techniques.

- Digital autoradiography using phosphor imaging plate technique and filmless electronic autoradiography were compared.

- ${ }^{133} \mathrm{Ba}$ polymethylmethacrylate standards were developed to determine the counting efficiency for electronic autoradiography.

- Good correlation between the two autoradiography methods were obtained in this study.

\section{A B S T R A C T}

The spatial distribution of barium activity in granitic rocks was measured with two autoradiography techniques; digital autoradiography using phosphor imaging plate technique (Fuji 5100) and filmless electronic autoradiography (i.e. The BeaQuant ${ }^{\mathrm{TM}}$ ), which is based on a gas detector incorporated in a micromesh Parallel Ionization Multiplier (PIM). Rock cubes taken from a diffusion experiment that were in contact with ${ }^{133}$ Ba tracer were measured to determine diffusion profiles. In addition, the spatial distribution of ${ }^{133} \mathrm{Ba}$ in the samples was determined. Polymethyl methacrylate standards for ${ }^{133} \mathrm{Ba}$ were developed to determine the counting efficiency for electronic autoradiography. Good visual correlation between the two autoradiography methods were obtained in this study. The results of the experiments presented here can be utilized in future studies on the diffusion behavior of barium in granitic rocks.

\section{Introduction}

Digital autoradiography using the phosphor imaging plate technique (IP) is based on the interaction of particles with a photostimulable phosphor screen containing BaFBr:Eu ${ }^{2+}$ crystals. The energy of the radiation emitted by the radionuclide converts $\mathrm{Eu}^{2+}$ to $\mathrm{Eu}^{3+}$, which liberates electrons to the conduction band of the phosphor crystals. These electrons are then trapped in bromine vacancies in the structure. Exposure to stimulating laser light of $633 \mathrm{~nm}$ releases the trapped electrons back to the conduction band of the crystals and converts $\mathrm{Eu}^{3+}$ back to $\mathrm{Eu}^{2+}$. The process releases photons, which are collected in a photomultiplier tube (Upham and Englert, 2003; Sardini et al., 2015; Leblans et al., 2011; L'Annunziata, 2012). The linear dynamic range of film autoradiography is limited $\left(10^{2}\right)$ compared to electronic autoradiography, which covers 5 orders of magnitude, and the phosphor imaging screens $\left(10^{4}-10^{5}\right)$ (Kämäräinen et al., 2006). Consequently, the exposure time needs to be chosen carefully to avoid oversaturation. Additionally, the IPs are affected by signal fade, which limits the maximal exposure time considerably, which may be important for samples with low activities and particularly for quantitative measurements (Upham and Englert, 2003). The fading effect can be evaluated using a standard radioactive source.

BeaQuant ${ }^{\mathrm{TM}}$ is a filmless electronic autoradiography system based on coupling a micro patterned gaseous detector (MPGD) and Parallel Ionization Multiplier (PIM) device, which allows the measuring of activities without film or IP (Donnard et al., 2009; Sardini et al., 2016). It allows real-time counting of charged particle emission from the analyzed surface with very high sensitivity and linearity. In addition, BeaQuant $^{\mathrm{TM}}$ enables real-time visualization of the data. The user is able to stop the acquisition at any moment and thus optimize the time of acquisition, which is a clear benefit compared to the traditional digital autoradiography techniques. The spatial resolution of the BeaQuant ${ }^{\mathrm{TM}}$

\footnotetext{
* Corresponding author.

E-mail address: eveliina.muuri@helsinki.fi (E. Muuri).
} 
has been observed to reach $35 \mu \mathrm{m}$ FWHM with ${ }^{14} \mathrm{C}$ labeling (Donnard et al., 2009), which is close to that of the IP technique, with which a spatial resolution of $20 \mu \mathrm{m}$ can be achieved (Sammaljärvi et al., 2017).

Autoradiography has been widely used in, for example, investigating radionuclide contaminations under decommissioning (Fichet et al., 2012; Leskinen et al., 2013) and in studying the sorption and diffusion properties of radionuclides in rock (Ittner and Allard, 1990; Pinnioja et al., 1984). It has been concluded in previous sorption and diffusion studies related to the final disposal of spent nuclear fuel that the rock heterogeneity may have a significant effect on the transport properties of radionuclides in granitic rock (Voutilainen et al., 2017). As a consequence, in order to understand the transport of radionuclides in granitic rock, it is necessary to characterize the matrix porosity and water conducting structures of the rock (Kelokaski et al., 2006). The porosities and pore structures of granitic rock have been studied in detail with the ${ }^{14} \mathrm{C}$-polymethylmetacrylate (C-14-PMMA) technique (Hellmuth et al., 1994; Siitari-Kauppi, 2002) which is based on the phosphor imaging technique that is also called digital autoradiography and film autoradiography methods. The image analysis of the C-14-PMMA technique has been especially developed to respond to the needs in structure characterization regarding the transport of trace elements in the final disposal of spent nuclear fuel (Sammaljärvi et al., 2012). However, numerical data of the activity distribution is not directly accessible in the widely used digital autoradiography technique using a phosphor imaging plate as conversion from an arbitrary unit called Digital Luminescence Unit (DLU) to activity is needed using a calibration curve (Sammaljärvi et al., 2016; L'Annunziata, 2003). In the C-14-PMMA technique, grey level values for different ${ }^{14} \mathrm{C}$ activities in the rock volume are obtained, which are converted into optical densities, to activities and finally to porosities (Siitari-Kauppi, 2002). With the new BeaQuant ${ }^{\mathrm{TM}}$ method, numerical data of the particle emissions can be obtained and the activities can be measured directly from the sample without using any films (Voutilainen et al., 2018).

The final disposal of spent nuclear fuel in Finland is planned to start in the 2020s in a geological repository in Olkiluoto and a similar concept has been considered, for example in Sweden (Posiva, 2012; Svensk Kärnbränslehantering AB, 2016). The geological repository investigated in these countries is based on a multiple release barrier system called the KBS-3 concept (Posiva, 2012). The barriers in the system include the physical form of the fuel, the copper disposal canister, the bentonite buffer, the tunnel backfill and the surrounding bedrock (Posiva, 2012). Each of the barriers in the system provide characteristic mechanic protection and isolation from the environment. The granitic bedrock surrounding the repository has been under extensive investigation because it acts as the final barrier between the spent nuclear fuel and the biosphere (Poteri et al., 2014). The bedrock can provide additional retention for radionuclides in flowing water by matrix diffusion into the water filled pore structure of the rock and, furthermore, by sorption onto the available mineral surfaces (Dai et al., 2007; Trinchero et al., 2017).

In this work, the spatial distribution of ${ }^{133} \mathrm{Ba}$ activity from the emission of Auger and conversion electrons in granitic rock cubes obtained from the Olkiluoto and Grimsel sites was studied by comparing two autoradiography methods; digital autoradiography using the IP plate technique (Fuji 5100) and electronic autoradiography e.g. BeaQuant ${ }^{\mathrm{TM}} .{ }^{133} \mathrm{Ba}$ was studied here because it is one of the nuclides studied in in situ diffusion experiments in Grimsel, Switzerland and Olkiluoto, Finland, and, consequently, knowledge of its spatial distribution in granitic rock is important (Muuri et al., 2018a). The rock cubes had been in contact with $\mathrm{a}^{133} \mathrm{Ba}$ tracer in diffusion experiments conducted in the laboratory to generate diffusion profiles of barium in the studied rocks. ${ }^{133} \mathrm{Ba}$ PMMA + HEMA standards were developed to determine the counting efficiency for both measurement systems for further analysis of the results. The theoretical passage of electrons from the rock samples and PMMA resin was simulated with Geant4 (Agostinelli et al., 2003), in order to predict the fraction of electrons reaching the sample surface and the detector. The results obtained in this study were used for evaluating the diffusion behavior of barium in granitic rocks.

\section{Materials and methods}

\subsection{Rocks}

The bedrock in the Olkiluoto area is heterogeneous and the main rock type at the depth of the repository facility is veined gneiss with shorter sections of pegmatitic granite (Toropainen, 2012). The bedrock in the Grimsel area, on the other hand, is mainly composed of Aare granite and granodiorite, which is homogeneous and medium grained (Kelokaski et al., 2010). The rocks chosen for the experiments in this study were veined gneiss (327 and 324) and pegmatitic granite (318) from Olkiluoto and granodiorite (GG) from Grimsel, where the numbers correspond to different drill cores in the Olkiluoto site (Sammaljärvi et al., 2017).

\subsection{Diffusion experiments}

The diffusion experiments were conducted on the $4.5 \mathrm{~cm} \times 3.0 \mathrm{~cm}$ x $1.0 \mathrm{~cm}$ rock pieces that had been sawed from rock cores cored from the Olkiluoto and Grimsel test sites. All surfaces except for one $4.5 \mathrm{~cm} \times 3 \mathrm{~cm}$ face was sealed with araldite resin so that one dimensional diffusion of ${ }^{133} \mathrm{Ba}$ could be studied. The rock pieces were attached to the top of the vessel so that the surface that was not sealed with araldite was in contact with groundwater simulants made to resemble the fracture groundwater from each of the two sites. The groundwater simulants are described in detail in (Muuri et al., 2018a). The rock pieces were equilibrated with the groundwater simulant $(20 \mathrm{~mL})$ for two weeks to ensure that the pieces were saturated with water. After this ${ }^{133} \mathrm{Ba}\left(\mathrm{BaCl}_{2}\right.$ in $0.1 \mathrm{M} \mathrm{HCl}$, Eckerst \& Ziegler, $\mathrm{BaCl}_{2}$ carrier $\left.1.30 \cdot 10^{-6} \mathrm{~g} / \mathrm{L}\right)$ and stable barium as $\mathrm{BaCl}_{2}\left(1 \cdot 10^{-6} \mathrm{M}\right)$ was added to the solution. The concentration decrease of the tracer was measured for three months by pipetting $19 \mathrm{~mL}$ of the solution for gamma spectroscopy of ${ }^{133} \mathrm{Ba}$ after which the solution was pipetted back into the vessel containing the rock piece. $19 \mathrm{~mL}$ was measured so that the measured activity would be large enough to keep the measurement time as short as possible so that the rocks would not get dry during the measurement. The concentration decrease was monitored first twice a day and later, and, after the decrease in tracer concentration had slowed down, once a week. The results obtained for the decrease of ${ }^{133} \mathrm{Ba}$ activity in solution were reported in (Muuri et al., 2018b). After ending the diffusion experiments, the rock surfaces that had been in contact with the tracer were studied with the digital and electronic autoradiography methods to determine the spatial distribution of activity in the sample volume as a function of intrusion depth.

\subsection{PMMA + HEMA standards}

${ }^{133} \mathrm{Ba}$ standards were prepared by mixing $3 \mathrm{~mL}$ of 2-hydroxy ethyl methacrylate (HEMA, Sigma Aldrich, 97\% purity, stabilized with $200 \mathrm{ppm}$ monomethyl ether hydroquinone) and $1 \mathrm{~mL}$ of methyl methacrylate (MMA, Merck, $<99 \%$ purity, stabilized with $100 \mathrm{ppm}$ hydroquinone) with $100 \mu \mathrm{L}(12 \mathrm{kBq})$ of ${ }^{133} \mathrm{Ba}$ tracer $\left(\mathrm{BaCl}_{2}\right.$ in $0.1 \mathrm{M} \mathrm{HCl}$, Eckerst \& Ziegler, $\mathrm{BaCl}_{2}$ carrier $1.30 \cdot 10^{-6} \mathrm{~g} / \mathrm{L}$ ) in a small glass vial (diameter $1.45 \mathrm{~cm}$ ). The HEMA + MMA solution was polymerized using chemical initiator 2,2-Azobis(2-methylpropionitrile) (AIBN, Sigma-Aldrich $98 \%$ purity) and heating to $55{ }^{\circ} \mathrm{C}$ after which the sample was sawn into thin layers of approximately $1 \mathrm{~mm}$ in thickness. The activity of the sawn samples was determined according to the weight of the sample compared to the weight of the whole sample and the activity of one standard was $1000 \pm 50 \mathrm{~Bq}$. The sawn HEMA + MMA polymer standard layers were embedded into an approximately $5 \mathrm{~mm}$ thick epoxy (Buehler EpoThin 2) resin in a plastic container (diameter 
$8.5 \mathrm{~cm}$ ). The epoxy resin was left to dry after which the plastic container was removed. The standards were then sawn into $4.5 \mathrm{~cm} \times 3.0 \mathrm{~cm} \times 0.5 \mathrm{~cm}$ pieces so that they could be placed into the BeaQuant ${ }^{\mathrm{TM}}$ sample holder and the surfaces were polished with silica powder. It was assumed that no significant amount of activity was lost during the polishing process. The surfaces of the samples were covered with $10 \mathrm{~nm}$ thick carbon coating with a Leica EM ACE200 carbon coater to achieve electrical conductivity which is necessary for the BeaQuant ${ }^{\mathrm{TM}}$ measurements. Different carbon coating thicknesses (1, 2, 510 and $15 \mathrm{~nm}$ ) were tested and $10 \mathrm{~nm}$ was found optimal for electrical conductivity and avoiding too much of an attenuating effect for the measurement of radioactivity.

\subsection{Digital autoradiography based on phosphor screens}

The surfaces of the rock cubes $(4.5 \mathrm{~cm} \times 3.0 \mathrm{~cm})$ that had been in contact with the ${ }^{133} \mathrm{Ba}$ tracer solution in the diffusion experiments were placed into exposure cassettes on phosphor screens (Fuji Imaging Plate BAS-TR2025, Fuji Photo Film Co., Ltd., Tokyo, Japan) for a sufficient exposure time. The rock surfaces were polished half a millimeter at a time, after which the surfaces were exposed again in order to obtain the intrusion depth of barium in the rock. The exposure time was $24 \mathrm{~h}$ for the first surfaces that were studied. As the surfaces were polished off layer by layer to study the intrusion depth of ${ }^{133} \mathrm{Ba}$, the activity decreased with depth and the exposure time was prolonged up to one week. After exposure, the imaging plates were scanned with a Fujifilm Life Sciences Imaging Systems FLA5100 with $10 \mu \mathrm{m}$ resolution. The data obtained from the scans was stored as digital files and analyzed with the image analysis program Aida (Raytest Isotopenmessgeräte $\mathrm{GmbH}$, Straubenhardt, Germany).

\subsection{Electronic autoradiography based on MPGD (BeaQuant $\left.{ }^{\mathrm{TM}}\right)$}

The same surfaces that were studied with digital autoradiography $(4.5 \mathrm{~cm} \times 3.0 \mathrm{~cm})$ were also studied with BeaQuant ${ }^{\mathrm{Tm}}$. The samples were coated with carbon to ensure electrical conductivity on the surface and carefully cleaned with compressed air to remove any dust or impurities. The samples were placed in the BELA sample holder made for geological samples $(4.5 \mathrm{~cm} \times 3.0 \mathrm{~cm} \times 0.9 \mathrm{~cm})$ and measured with measurement settings configured for ${ }^{133} \mathrm{Ba}$. The BELA sample holder has been tuned for alpha and beta emitters. ${ }^{133} \mathrm{Ba}$ emits Auger electrons and conversion electrons (Table 1) that can be detected by the micro patterned gaseous detection system. Charged particles ionize the gas in the gas chamber creating electrons that are multiplied in the amplification space of the system (Fig. 1). There is a voltage difference between the two micromeshes of the system, which allows the electrons to drift onto the two dimensional pixelated reading floor revealing the spatial distribution of activity in the sample.

\subsection{Geant4 simulations for determining the ${ }^{133}$ Ba detection efficiency with BeaQuant $^{\mathrm{TM}}$}

Geant4 (GEometry ANd Tracking 4, version 4.10.02.p02) is a powerful toolkit allowing the simulation of the transport of particles

Table 1

Energies and intensities of the electrons emitted by ${ }^{133} \mathrm{Ba}$ (NuDat).

\begin{tabular}{llll}
\hline Emission type & Energy (keV) & Intensity (\%) & Standardized intensity (\%) \\
\hline Auger $^{-}$ & 4.05 & 138.0 & 62.1 \\
${\text { Conversion } \mathrm{e}^{-}}^{-}$ & 17.18 & 10.6 & 4.8 \\
Auger $^{-}$ & 30.20 & 14.2 & 6.4 \\
Conversion $^{-}$ & 43.63 & 4.0 & 1.8 \\
Conversion $\mathrm{e}^{-}$ & 45.01 & 48.1 & 21.7 \\
Conversion $\mathrm{e}^{-}$ & 75.54 & 7.3 & 3.3 \\
Sum & & 222.16 & 100 \\
& & & \\
\end{tabular}

through matter (Agostinelli et al., 2003). A specific list of electromagnetic processes was constructed. Here Geant4 was used to predict the proportion of ${ }^{133} \mathrm{Ba}$ Auger and conversion electrons that is emitted out from veined gneiss, pegmatitic granite and granodiorite rock sample surface and from PMMA + HEMA standard sample.

The ${ }^{133} \mathrm{Ba}$ PMMA + HEMA standard was first used to determine the detection efficiency $\varepsilon$ of the BeaQuant ${ }^{\mathrm{TM}}$ for ${ }^{133} \mathrm{Ba}$ emissions. The number of electrons counted by the detector $N_{O}\left(\mathrm{cps} / \mathrm{mm}^{2}\right)$ was compared with the number of electrons emerging from the sample surface $A_{S, \text { out }}$ (i.e. the surface analyzed with the BeaQuant ${ }^{\mathrm{TM}}$ ) to the detector. (Eq. (1)).

$\varepsilon=\frac{N_{0}}{A_{S, \text { out }}}$

However, only the volumetric activity $A_{V}$ of the ${ }^{133} \mathrm{Ba}$ PMMA + HEMA standard was known $\left(6500 \mathrm{~Bq} / \mathrm{cm}^{3}\right)$. Geant4 was also used to evaluate the emission fraction $G_{e}$, defined as the ratio between the number of electrons emitted at the analyzed sample surface and the number of electrons emitted in the sample volume. The $G_{e}$ allows to convert the volumetric activity to the surface activity. It depends on the material density, the radioactive sample thickness $d_{S}$, and the emission energy of the electrons and the range $d$ of electrons in the matter.

Geant 4 has also been used to determine the volume of the sample that is needed to be considered for the conversion from volumetric to surface activity. The electrons emitted from deeper than their maximum range $d_{\max }$ are not able to reach the analyzed sample surface and need not to be taken into account in the calculations. The thicknesses $d_{s}$ of the measured rock samples varied from 5 to $9 \mathrm{~mm}$ and the one of PMMA + HEMA standard was $8 \mathrm{~mm}$.

The maximum range of electrons emitted from ${ }^{133} \mathrm{Ba}$ corresponding to the most energetic electron (conversion electron with $75.54 \mathrm{keV}$ energy in the case of ${ }^{133} \mathrm{Ba}$ ) was calculated in PMMA + HEMA standard (density of $1.2 \mathrm{~g} / \mathrm{cm}^{3} ; d_{\max }=80.2 \mu \mathrm{m}$ ) and in rock samples (density of $\left.2.7 \mathrm{~g} / \mathrm{cm}^{3} ; \quad d_{\max }=38.6 \mu \mathrm{m}\right)$ using Geant 4 . Because for both the PMMA + HEMA standard and the rock samples $d_{S}>d_{\max }$ a volume of thickness equal to $d_{\max }$ can be considered to estimate $G_{e}$ and then perform the conversion between volumetric and surface activities (or conversely) (Eq. (2)).

$A_{S, \text { out }}=A_{V} \cdot d_{\max } \cdot G_{e}$

The emission fraction $G_{e}$ was calculated in the PMMA + HEMA standard and in granitic rock using $10^{7}$ electrons in the simulations to ensure a good statistical analysis. For each emitted electron, its energy was selected in the energy distribution of ${ }^{133} \mathrm{Ba}$ (Table 1 ) and its emission depth was randomly selected between 0 ( = surface) and the maximum range $d_{\max }$ of ${ }^{133} \mathrm{Ba}$ in the studied material. The emission fraction $G_{e}$ was calculated to be $2.85 \%$ for PMMA from a volume of thickness $80.2 \mu \mathrm{m}$, and $2.82 \%$ for the rock from a volume of thickness $38.6 \mu \mathrm{m}$.

Using equation (2), the surface activity of the ${ }^{133} \mathrm{Ba}$ PMMA + HEMA standard can be estimated from the known volumetric activity, to be then used in Equation (1) to determine the detection efficiency of the detector. $N_{O}$ from BeaQuant ${ }^{\mathrm{TM}}$ measurements can be corrected using the detection efficiency, to calculate the true surface activity $A_{S \text {, out }}$ (Equation (1)). Equation (2) can provide a good estimation of the volumetric activity in the rock samples. Depending on the application, either surface or volumetric activity can be used. Here either can be used, whereas in, for example, porosity mapping, surface activity is more interesting and in decommissioning volumetric activity described here is more important.

\section{Results and discussion}

First, the standards were measured with BeaQuant ${ }^{\mathrm{TM}}$ in order to determine the detection efficiency of the measurement system for ${ }^{133} \mathrm{Ba}$ with an acquisition time of $78 \mathrm{~h}$ in order to get a good statistical 


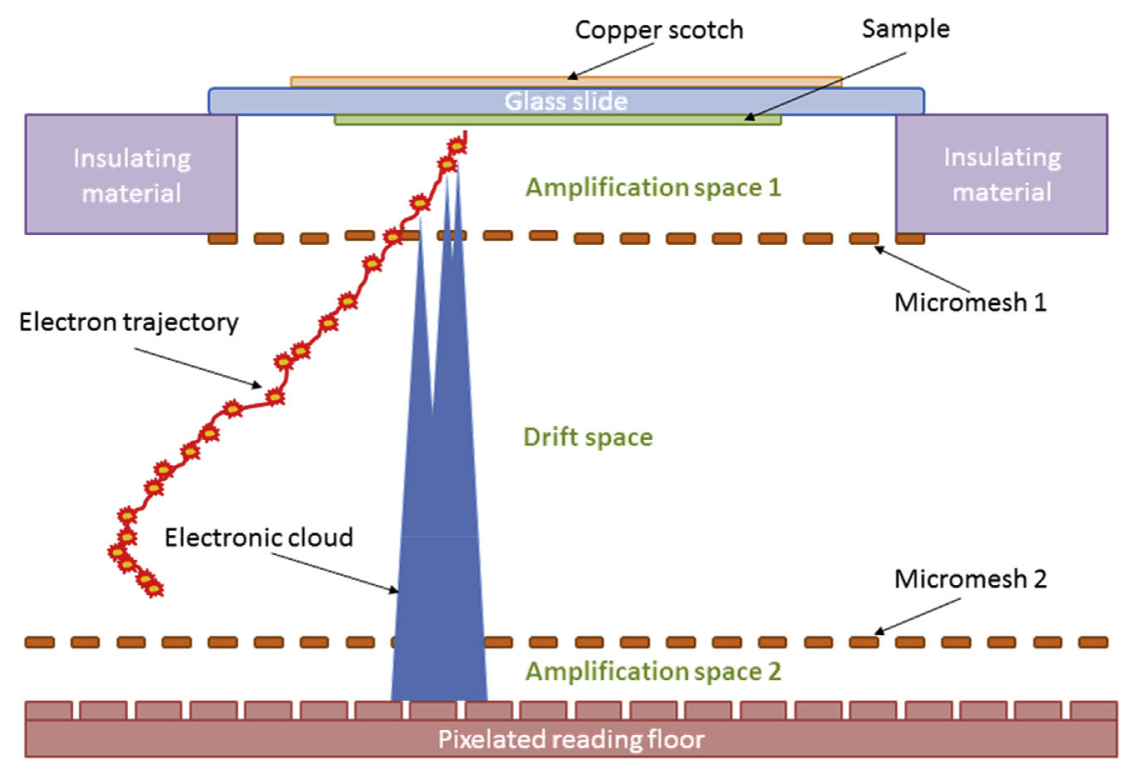

Fig. 1. A schematic representation of the working principle of BeaQuant ${ }^{\mathrm{TM}}$ (with courtesy of Ai4r).

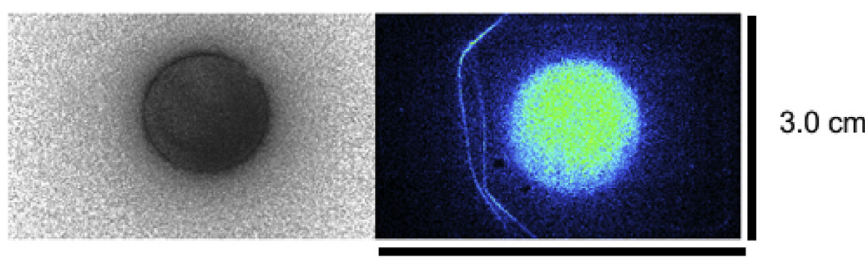

$4.5 \mathrm{~cm}$

Fig. 2. The digital autoradiograph (left) and BeaQuant ${ }^{\mathrm{TM}}$ image (right) of the ${ }^{133} \mathrm{Ba}$ PMMA + HEMA standard. The lines on the right side of the BeaQuant ${ }^{\mathrm{TM}}$ image are caused by scratches on the sample that caused disturbances in the acquisition. The activity of the sample was $6500 \mathrm{~Bq} / \mathrm{cm}^{3}$ and the diameter of the standard was $1.45 \mathrm{~cm}$. The exposure time for FLA was $6 \mathrm{~h}$ and the measurement time for BeaQuant ${ }^{\mathrm{TM}} 68 \mathrm{~h}$.

certainty for the results. The standards were also studied with digital autoradiography to compare the two autoradiography methods (Fig. 2). In addition, the standards were measured with gamma spectroscopy to compare the results obtained with BeaQuant ${ }^{\mathrm{TM}}$ to obtain more confidence in the activity results as the gamma measurement results confirmed the activity of the standard sample $(1069 \mathrm{~Bq})$. These values were used to determine the total number of electrons emitted from the standard sample, which was then compared with the number of counts measured with BeaQuant ${ }^{\mathrm{TM}}$. A detection efficiency of $82.1 \%$ was obtained for ${ }^{133} \mathrm{Ba}$. The detection efficiency means that $82.1 \%$ of ${ }^{133} \mathrm{Ba}$ electrons can access the detector in the BeaQuant ${ }^{\mathrm{TM}}$ system in the experiments, compared to the amount of electrons that are expected to reach the analyzed surface according to the Geant 4 calculations. A total efficiency for ${ }^{133} \mathrm{Ba}$ taking into account the fraction of electrons to exit the sample and the detection efficiency of BeaQuant ${ }^{\mathrm{TM}}$ was found to be $2.34 \%(0.82 \times 2.85 \%)$. Considering a sample volume of thickness equal to the maximum range $d_{\max }$ of electrons in the relevant material ( $80.2 \mu \mathrm{m}$ and $38.6 \mu \mathrm{m}$ in PMMA and granite, respectively) the same total efficiency correction factor could be used for both PMMA and rock samples (the fraction of electrons $G_{e}$ reaching the sample surface was $2.85 \%$ for the PMMA sample, and $2.82 \%$ for the rock sample; see section 2.5). As the detector gives a linear response as a function of activity (Donnard et al., 2009), one standard sample was sufficient to determine the total efficiency correction factor for the measurement system.

Second, the rock samples from the diffusion experiments were studied with the novel electronic autoradiography method and the results were compared with results from digital autoradiography. The main interest in BeaQuant ${ }^{\mathrm{TM}}$ is that it is an online measurement system and the measurement time can be optimized real-time. The images obtained from BeaQuant ${ }^{\mathrm{TM}}$ were in good agreement with the digital autoradiographs as similar features in the samples could be observed with both techniques with similar resolutions (Fig. 3). The visual correlation was best with the veined gneiss samples and weakest with pegmatitic granite. BeaQuant ${ }^{\mathrm{TM}}$ is very sensitive to disturbances in the sample surface, such as, weak conductivity and surface roughness. Although these effects could not be completely eliminated, it is possible they still influenced the results of the pegmatitic granite and granodiorite, which are more likely to suffer from cracking during sawing and polishing due to their brittle properties compared to veined gneiss.

The diffusion paths of barium in veined gneiss followed the biotite and cordierite grains in the rock, which has been observed in previous studies as well (Muuri et al., 2018a). The interlamellar spaces of biotite in veined gneiss from Olkiluoto have been found to be filled with muscovite, illite and kaolinite as well as cordierite partly altered to clay minerals with large specific surface area and thus large sorption capacity (Sammaljärvi et al., 2017), making the biotite veins preferable sorption sited and migration paths for sorbing radionuclides. The diffusion of barium in pegmatitic granite, on the other hand, was dominated by micro fractures cutting large feldspar grains and grain boundaries of the minerals in the rock (Fig. 3). The pegmatitic granite in Olkiluoto is very weakly altered and consisted of large grains with low porosity so that the porosity of the rock is dominated by the grain boundaries and intergranular porosity (Sammaljärvi et al., 2017). It can be seen in Fig. 3 that there are only few dominating micro fractures and grain boundaries in the pegmatitic granite sample, which explains the small diffusion and sorption compared to other samples. The diffusion results are discussed numerically in (Muuri et al., 2018b). The diffusion of barium in Grimsel granodiorite was more homogeneous than in the Olkiluoto rocks, which can be seen in the BeaQuant ${ }^{\mathrm{TM}}$ images. This is due to the porosity pattern of Grimsel granodiorite, which is homogeneous and all the major minerals; quartz, biotite, feldspars are found to be porous (Kelokaski et al., 2006). Additionally, the intrusion depth of barium was found to be largest in Grimsel granodiorite, which is most probably due to the high connectivity of Grimsel granodiorite porosity compared to the other rock samples.

The surfaces were polished $0.5 \mathrm{~mm}$ at a time in order to measure the intrusion of ${ }^{133} \mathrm{Ba}$. The measurement with autoradiography was repeated so that the mean activities of the sample surfaces were determined as a function of intrusion depth (Fig. 4). The intrusion depth 
a)

b)
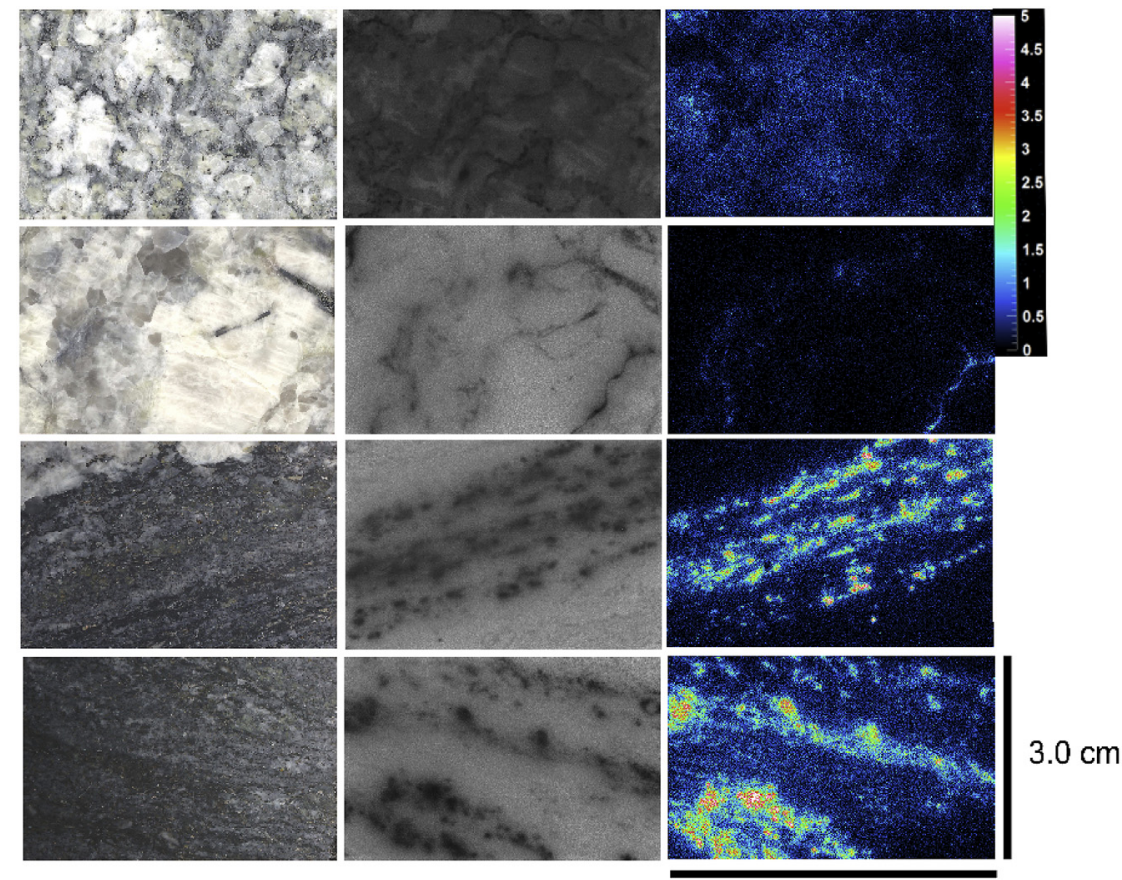

$4.5 \mathrm{~cm}$
Fig. 3. Scanned photographs (left), digital autoradiographs (middle) and BeaQuant ${ }^{\mathrm{TM}}$ images (right) of a) Grimsel granodiorite (GG), b) pegmatitic granite (318), c) veined gneiss (324) and d) veined gneiss (327). In the digital autoradiography, the darkest areas correspond to largest activities, whereas in the BeaQuant ${ }^{\mathrm{TM}}$ images the brightest areas correspond to largest activities. The scale of the samples is given in the figure and the color scale represents the cps detected by BeaQuant ${ }^{\mathrm{TM}}$ per pixel. In the digital autoradiographs only the difference in gray levels is detected, not numerical counts emitted by the sample (Muuri et al., 2018b). (For interpretation of the references to color in this figure legend, the reader is referred to the Web version of this article.)

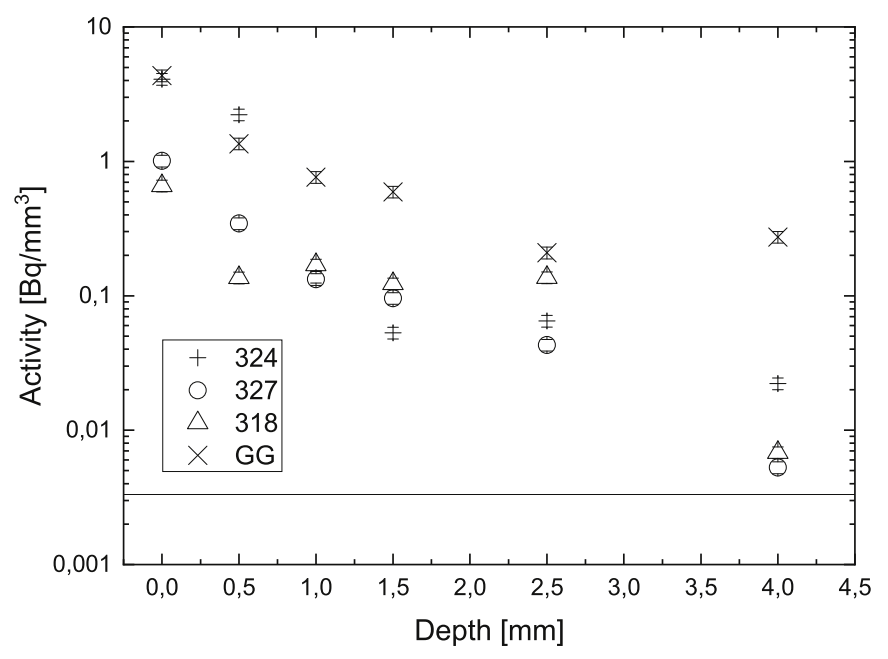

Fig. 4. Intrusion depth of ${ }^{133} \mathrm{Ba}$ in Grimsel granodiorite (GG), pegmatitic granite (318) and veined gneiss (324 and 327) determined with the BeaQuant ${ }^{\mathrm{TM}}$ (Muuri et al., 2018b). The black line represents the minimum detectable activity of ${ }^{133} \mathrm{Ba}$ with BeaQuant ${ }^{\mathrm{TM}}$ determined with a background sample.

and activity of ${ }^{133} \mathrm{Ba}$ on the first measured surface $(\mathrm{x}=0)$ was found to be largest in granodiorite and the activity of ${ }^{133} \mathrm{Ba}$ decreased to levels near the minimum detectable activity (MDA) only after about $4 \mathrm{~mm}$ into the rock. Additionally, the activities on the first studied surface and intrusion depth were lowest in pegmatitic granite, where activity levels near the MDA was already reached at about $0.5 \mathrm{~mm}$ depth. As the points in the profile have been determined as a mean activity for the surface although sorption on the surface is heterogeneous, there might be dispersion in the profiles. On the other hand, the more homogeneous structure of Grimsel granodiorite can be seen as less dispersion in the profile results.

The diffusion results of the two veined gneiss samples, 324 and 327, were very different from each other as the activity of ${ }^{133} \mathrm{Ba}$ on the first studied surface of 324 was five times higher than that of 327 . This can be caused by the heterogeneous distribution of mineralogy and porosity in this rock type (Sammaljärvi et al., 2017), which can have a huge effect on the diffusion properties of radionuclides over such a small scale. Although the measured porosities for $324(0.77 \%)$ and 327 $(1.1 \%)$ are quite similar, the porosity is distributed very heterogeneously, as there are many highly porous patches interspersed in lowly porous matrix (Sammaljärvi et al., 2017). It is possible that the 324 sample used in this study is from a higher porosity area whereas the 327 sample has a lower matrix porosity.

The decrease of ${ }^{133} \mathrm{Ba}$ activity in solution in the diffusion experiments has been reported in detail in (Muuri et al., 2018b). The mass balance of ${ }^{133} \mathrm{Ba}$ could be evaluated in the experiments by comparing the activity of ${ }^{133} \mathrm{Ba}$ measured in solution in the end of the diffusion experiment and the activity of ${ }^{133} \mathrm{Ba}$ in rock to the initial ${ }^{133} \mathrm{Ba}$ activity in the experiment. It was discovered that in all studied rocks, the measured ${ }^{133} \mathrm{Ba}$ activity in solution at the end of the experiment (approximately $1000 \mathrm{~Bq}$ ) and in rock (approximately $2000 \mathrm{~Bq}$ ) was on average $65 \%$ of the initial ${ }^{133} \mathrm{Ba}$ activity in the experiments (4600 Bq). This is most probably because some of the activity was lost on the surfaces of the vessel, on the araldite sealing of the rock and during the polishing process. However, in transport obtaining a $100 \%$ mass balance in transport experiments in laboratory and in situ is very challenging (Soler et al., 2015). As a consequence, the mass balance can be considered adequate, especially considering all the uncertainties in the experiments and that this was the first attempt in measuring ${ }^{133} \mathrm{Ba}$ quantitatively with BeaQuant ${ }^{\mathrm{TM}}$.

\section{Conclusions}

The BeaQuant ${ }^{\mathrm{TM}}$ was found to be a practical tool for quantitatively assessing the heterogeneous diffusion of ${ }^{133} \mathrm{Ba}$ in rock samples. The measurement does not require separate imaging plates or films and it allows users to optimize the acquisition time during the measurement as the data is visualized in real-time. In addition, as the detector gives a linear response as a function of activity, one calibration standard is sufficient for converting the count rates into activities in the activity range. However, the measurement system is sensitive to disturbances, and that is why it is good to confirm with, for example, digital autoradiography that the signals detected are caused by radioactivity and 
not by artefacts in the sample. A good visual correlation between electronic and digital autoradiography results were obtained in this study. In addition, electronic autoradiography was found to be useful in quantifying the intrusion of ${ }^{133} \mathrm{Ba}$ in granitic rock. BeaQuant ${ }^{\mathrm{TM}}$ is a new autoradiography method so future research is needed to optimize its use for geological samples.

\section{Acknowledgements}

This work was supported by the Finnish Research Program on Nuclear Waste Management KYT2018.

\section{Appendix A. Supplementary data}

Supplementary data to this article can be found online at https:// doi.org/10.1016/j.apradiso.2019.04.026.

\section{References}

Agostinelli, S., et al., 2003. Geant4 - a simulation toolkit. Nucl. Instrum. Methods Phys. Res. 506, 250-303.

Dai, Z., Wolfsberg, A., Lu, Z., Reimus, P., 2007. Upscaling matrix diffusion coefficients for heterogeneous fractured rocks. Geophys. Res. Lett. 34 (7).

Donnard, J., Thers, D., Servagent, N., Luquin, L., 2009. High spatial resolution in $\beta$ imaging with a PIM device. IEEE Trans. Nucl. Sci. 56.

Fichet, P., Bresson, F., Leskinen, A., Goutelard, F., Ikonen, J., Siitari-Kauppi, M., 2012. Tritium analysis in building dismantling process using digital autoradiography. J. Radioanal. Nucl. Chem. 291, 869-875.

Hellmuth, K.H., Lukkarinen, S., Siitari-Kauppi, M., 1994. Rock matrix studies with carbon-14-polymethylmethacrylate (PMMA); method development and applications. Isotopenpraxis Environ. Health Stud. 30, 47-60.

Ittner, T., Allard, B., 1990. Diffusion of strontium, technetium, iodine and cesium in granitic rock. Radiochim. Acta 49, 101-106.

Kelokaski, M., Siitari-Kauppi, M., Kauppi, I., Hellmuth, K.-H., Möri, A., Biggin, C., Kickmaier, W., Inderbitzin, L., Martin, A., 2010. Pore Space Geometry Project Characterisation of Pore Space Geometry by ${ }^{14} \mathrm{C}-\mathrm{MMA}$ Impregnation. Nagra Technical Report 05-03.

Kelokaski, M., Siitari-Kauppi, M., Sardini, P., Möri, A., Hellmuth, K.-H., 2006. Characterisation of pore space geometry by 14C-PMMA impregnation -development work for in situ studies. J. Geochem. Explor. 90, 45-52.

Kämäräinen, E.-L., Haaparanta, M., Siitari-Kauppi, M., Koivula, T., Lipponen, T., Solin, O., 2006. Analysis of ${ }^{18} \mathrm{~F}$-labelled synthesis products on TLC plates: comparison of radioactivity scanning, film autoradiography, and a phosphoimaging technique. Appl. Radiat. Isot. 64, 1043-1047.

L'Annunziata (Ed.), 2012. Handbook of Radioactivity Analysis, third ed.

Leblans, P., Vandenbroucke, D., Willems, P., 2011. Storage phosphor for medical imaging. Materials 4, 1034-1086.

Leskinen, A., Fichet, P., Siitari-Kauppi, M., Goutelard, F., 2013. Digital autoradiography (DA) in quantification of trace level beta emitters on concrete. J. Radioanal. Nucl. Chem. 298, 153-161.
Muuri, E., Matara-aho, M., Puhakka, E., Ikonen, J., Martin, A., Koskinen, L., SiitariKauppi, M., 2018a. The sorption and diffusion of 133Ba in crushed and intact granitic rocks from the Olkiluoto and Grimsel in-situ test sites. Appl. Geochem. 89, 138-149.

Muuri, E., Sorokina, S., García, D., Grivé, M., Bruno, J., Koskinen, L., Martin, A., SiitariKauppi, M., 2018b. The in-diffusion of ${ }^{133} \mathrm{Ba}$ in granitic rock cubes from the Olkiluoto and Grimsel in-situ test sites. Appl. Geochem. 92, 188-195.

NuDat http://www.nucleide.org/NucData.htm.

Pinnioja, S., Jaakkola, T., Miettinen, J.K., 1984. Comparison of batch and autoradiographic methods in sorption studies of radionuclides in rock and mineral samples. Mater. Res. Soc. Symp. Proc. 26, 979-984.

Posiva, 2012. Safety Case for the Disposal of Spent Nuclear Fuel at Olkiluoto - Models and Data for the Repository System 2012. POSIVA-2013-01. Posiva Oy.

Poteri, A., Nordman, H., Pulkkanen, V.-M., Smith, P., 2014. Radionuclide transport in the repository near-field and far-field. Posiva report 2014-02. ISBN 978-951-652-240-4.

Sammaljärvi, J., Jokelainen, L., Ikonen, J., Siitari-Kauppi, M., 2012. Free radical polymerisation of MMA with thermal initiator in brick and Grimsel granodiorite. Eng. Geol. 135-136, 52-59.

Sammaljärvi, J., Lindberg, A., Voutilainen, M., Kuva, J., Ikonen, J., Siitari-Kauppi, M., Pitkänen, P., Koskinen, L., 2017. Multi-scale study of the mineral porosity of veined gneiss and pegmatitic granite from Olkiluoto, Western Finland. J. Radioanal. Nucl. Chem. 314, 1557-1575.

Sammaljärvi, J., Shroff Rama, M., Ikonen, J., Muuri, E., Hellmuth, K.-H., Siitari-Kauppi, M., 2016. Free radical polymerisation of methacrylates with thermal initiator in clay rock. Eng. Geol. 210, 70-83.

Sardini, P., Angileri, A., Descostes, M., Duval, S., Oger, T., Patrier, P., Rividi, N., SiitariKauppi, M., Toubon, H., Donnard, J., 2016. Quantitative autoradiography of alpha particle emission in geo-materials using the BeaQuant ${ }^{\mathrm{TM}}$ system. Nucl. Instrum. Methods Phys. Res. 833, 15-22.

Sardini, P., Caner, L., Mossler, P., Mazurier, A., Hellmuth, K.-H., Graham, R., Rossi, A., Siitari-Kauppi, M., 2015. Calibration of digital autoradiograph technique for quantifying rock porosity using ${ }^{14}$ C-PMMA method. J. Radioanal. Nucl. Chem. 303 (1), $11-23$.

Siitari-Kauppi, M., 2002. Development of 14C-Polymethylmethacrylate Method for the Characterisation of Low Porosity Media: Application to Rocks in Geological Barriers of Nuclear Waste Storage. PhD thesis, University of Helsinki Report Series in Radiochemistry 17.

Soler, J.M., Landa, J., Havlova, V., Tachi, Y., Ebina, T., Sardini, P., Siitari-Kauppi, M., Eikenberg, J., Martin, A.J., 2015. Comparative modeling of an in-situ diffusion experiment in granite at the Grimsel Test Site. J. Contam. Hydrol. 179, 89-101.

Svensk Kärnbränslehantering, A.B., 2016. Äspö Hard Rock Laboratory Annual Report 2015. Technical Report TR-16-10.

Toropainen, V., 2012. Core Drilling of Repro Drillholes in Onkalo at Olkiluoto 2010-2011. Posiva Working Report 78.

Trinchero, P., Molinero, J., Deissmann, G., Svensson, U., Gylling, B., Ebrahimi, H., Hammond, G., Bosbach, D., Puigdomenech, I., 2017. Transport Porous Media 116, 73-90.

Upham, L.V., Englert, D.F., 2003. In: L'Annunziata, M.F. (Ed.), Handbook of Radioactivity Analysis, second ed. Elsevier science, Amsterdam, pp. 179-237.

Voutilainen, M., Sammaljärvi, J., Muuri, E., Donnard, J., Duval, S., Siitari-Kauppi, M., 2018. Digital autoradiography on C-14-labelled PMMA impregnated rock samples using the Beaver ${ }^{\mathrm{TM}}$. MRS Advances 3 (21), 1161-1166.

Voutilainen, M., Siitari-Kauppi, M., Sardini, P., Kekäläinen, P., Muuri, E., Timonen, J., Martin, A., 2017. Modelling transport of cesium in Grimsel granodiorite with heterogenous structure and dynamic update of Kd. Water Resour. Res. 53, 9245-9265. 